\title{
Potential of Porous Silicon Doped With Gold Nanoparticles in Detection of Biogenic Amine. Porous Silicon Used in the Detection of Biogenic Amines
}

\author{
Francisco Severiano Carrillo* \\ Instituto Politécnico Nacional, Center for Research in Applied Biotechnology Unit Tlaxcala, Mexico
}

Submission: February 13, 2017; Published: March 06, 2017

*Corresponding author: Francisco Severiano Carrillo, Instituto Politécnico Nacional, Center for Research in Applied Biotechnology Unit Tlaxcala, Mexico, Tel: (52) 01248487 0765; E-mail : balarama_1@yahoo.com.mx

\begin{abstract}
Due to its properties porous silicon is a material with high potential to be applied in bio-delivery carriers and biosensors. To enhancement the capacity of porous silicon as biosensor, gold nanoparticles are introduced in its structure. One of the most used methods to obtain porous silicon/Au nanoparticles is metal salt-assisted chemical etching. The high surface of porous silicon matrix and the Au nanoparticles allow the increment of the sensitivity of the biosensor. This structure can be use as platform to got a biogenic amine optic biosensors. This kind of sensors (optic) are based on the changes of the signals related to the reactions between biogenic amines and the recognized element used (diamine oxidase).
\end{abstract}

Keywords: Electrochemistry; Etching; Metal ions; Porous silicon; Biosensor platform

\section{Introduction}

Porous silicon (PS) is a very promising material due to their interesting optical (luminescence at room temperature), electrical (change of the resistivity) and chemical properties (this kind of structures possess high surface area, and their open structure allows high reactivity). PS can be obtained by chemical etching in a solution of hydrofluoric acid (HF) and ethanol [1]. These porous structures are excellent candidates for devices in the fields of optoelectronics [2], biochemical [3], and biosensors [4]. The different characteristics of the PS as pore diameter and thickness can be controlled by the etching parameters (current density and time of etching) [1]. After the etching the internal surface of PS is hydrogen-terminated, which allows immobilize biomolecules [5]. Thanks to its properties, PS can be applied as a platform in the objection of optic or electronically biosensors. On the other hand, due to properties as: large surface area, scattering and absorption of visible light, high density of electrons and catalytic properties; gold nanoparticles has been used as catalyst [6], biosensor, bioanalytical element [7] and electrochemical detection platform [8]. For these reasons, the incorporation of gold nanoparticles in the structure of PS is with the objective of increase the sensibility of biosensors [9]. One of the areas where the application of biosensors is essential is in the food industry, especially in the quality control.

In recent years biogenic amines (BA) have been related with food intoxications. Because to their psychoactive or vasoactive effect as well as their use as quality standard in food. The principal symptoms that the BA produces are: skin rash, epigastric pain, disturbances of the gastrointestinal tract (this kind of health problems are treated with antihistamines). For these reasons BA are used as indicator for food quality. BA is produced by microbial decomposition in food with high content of proteins. Other important factors in BA generation are the maturation and storage of foodstuff (fish, meat, cheese, beer, wine, etc.) [10]. The quantity of BA in food is directly related with the biological process involved in the production process through which was obtained. BA such as putrescine, cadaverine and histamine are decomposition products of lysine, ornithine and histidine respectively. 


\section{Global Journal of Nanomedicine}

The consumption of large quantities of histamine could lead to scombrotoxicosis, while other BA is related to effects in respiratory distress, nausea, hyper or hypotension, as was mentioned before. For these reason is important to develop BA biosensors with high sensitivity. Actually there are different methods to measure the presence of BA, for example, histamine has been sensed by derivatisation with fluorescent reagents followed by chromatographic separation [11]. This method is tedious and required trained personal besides of expensive equipment. Other methods to measure the presence of BA are immunochemical methods, capillary electrophoresis and gas chromatographic methods, all these methods required long time of analysis and expensive equipment [11]. To reduce the time of BA sensing, some enzymatic methods and enzyme biosensors have been applied $[11,12]$. The objectives of the enzymes were the immobilization of the BA. This kind of biosensor shows advantages such as rapid analysis and few sample preparation.

\section{Introduction of gold nanoparticles in PS}

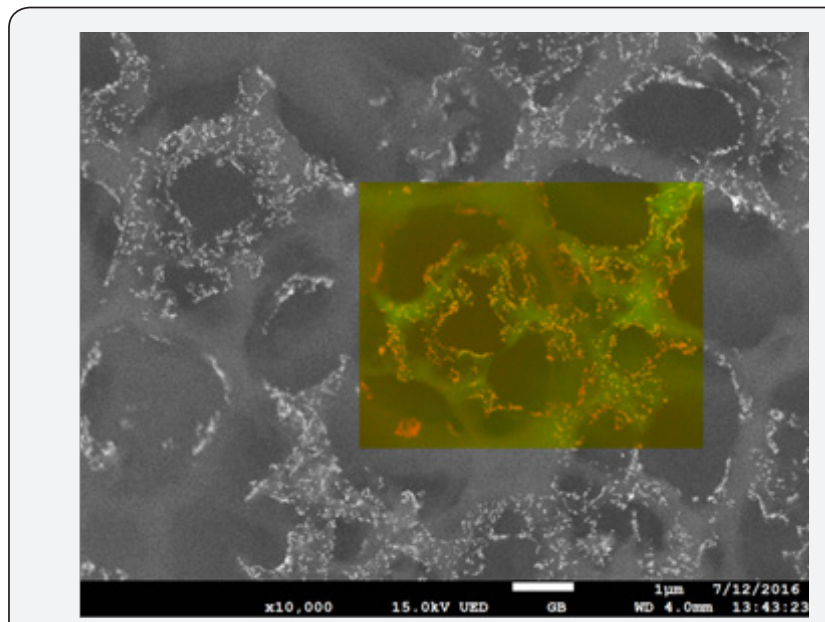

Figure 1: SEM image obtained with secondary electrons. The inset inside of the image is a composite signal of secondary (topographic information set as green color) and backscattered electrons (atomic number contrast image set as red). Thus, the brightest points on images are gold nanoparticles.

Several methods have been implemented to obtain porous silicon layers with metals in its structure, such as, sputtering, chemical vapor deposition, or by wet processes like, electroplating, electrolysis, plating, and immersing plating. Among these methods, Metal salt-assisted chemical etching is an easy and a low cost technique used to introduce metals in the PS surface [13]. Besides of this, the process of metal saltassisted chemical etching is rather simple and very fast. This technique is similar to the commonly used electrochemical attack in the PS manufacturing; but, in this process, using metal salt in the electrolyte. Additionally, it allows the tuning of the properties in PS with physical parameters (thickness, pore diameter, and doping level) [14]. Thickness can be controlled through the etching time; pore diameter is controlled by the used electrolyte; and doping level is controlled by the amount of metal salt supplied [14]. The size of the gold nanoparticles can be around $20 \mathrm{~nm}$ and the pore size around $1.5 \mu \mathrm{m}$. With help of SEM analysis can be demonstrate the incorporation of $\mathrm{Au}$ nanoparticles in PS structure, Figure 1, and X-ray energy dispersive spectroscopy (EDS) can confirm the introduction of gold nanoparticles. Raman spectroscopy obtained from PS and PS/Au samples, Figure 2, show an increment of the intensity which can be related to the surface enhancement originated by the $\mathrm{Au}$ presence in the surface $[14,15]$. This effect is very important in the amine detection process due to the increment of the signals related with the enzymatic reaction used to sensing the quantity of $\mathrm{AB}$ in food.

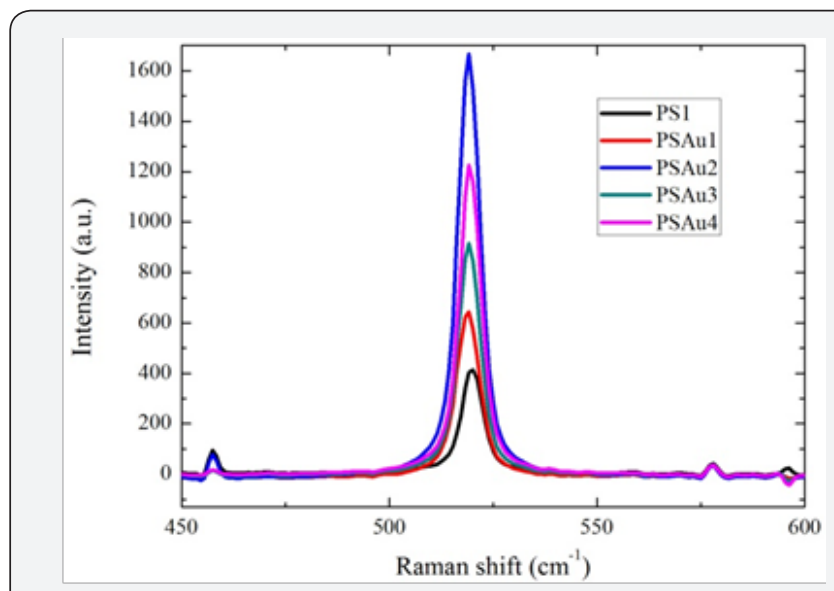

Figure 2: Raman spectra for PS (PS1) and PSAu (PSAu1PSAu4) samples with different quantities of $A u$ in the surface [14]. The presence of $A u$ in the PS origin an increment in the signal related to the $\mathrm{Si}\left(520 \mathrm{~cm}^{-1}\right)$. This can be related to the surface enhancement effect originated by the Au presence in the surface.

\section{Conclusion}

Porous structures with gold nanoparticles in its structure are excellent candidates for to be used as biosensors platforms since contribute to enhance their optical and chemical features. It is known that the correctly incorporation of some metal atoms and nanoparticles help to increase the luminescent emission, passivity the surface of the PS and even increase their conductivity, necessary characteristics to enhancement the sensivity of biosensor. The correct introduction of gold nanoparticles in the PS structure open the possibility to be used as a biosensor template and improve the performance of optoelectronic devices developed with PS.

\section{References}

1. Severiano F, García G, Castañeda L, Salazar Villanueva M, Flores Méndez J (2015) Importance of the Electrolyte in Obtaining Porous Silicon and How It Modifies the Optical and Structural Proprieties: Optical and Microstructural Investigation. Journal of Nanomaterials 6 pages.

2. Severianoa F, Garcíab G, Castañeda L (2014) Study of the electroluminescent properties of crystalline silicon wafers in devices based on junctions of indium-doped zinc oxide and porous silicon, Materials Science in Semiconductor Processing 27: 326-334. 


\section{Global Journal of Nanomedicine}

3. Jeffery L Coffer, Melanie A Whitehead, Dattatri K Nagesha, Priyabrata Mukherjee, Giridhar Akkaraju, et al. (2005) Porous silicon-based scaffolds for tissue engineering and other biomedical applications. physica status solidi 202: 1451-1455.

4. Soma Chattopadhyay, Xiuling Li, Paul W Bohn (2002) In plane control of morphology and tunable photoluminescence in porous silicon produced by metal-assisted electroless chemical etching, Journal of Applied Physics 91(9): 6134-6140.

5. Mathew FP, Alocilja EC (2005) Porous silicon-based biosensor for pathogen detection. Biosens Bioelectron 20(8): 1656-1661.

6. Lopez-Sanchez JA, Dimitratos N, Hammond C, Brett GL, Kesavan L, et al. (2011) Facile removal of stabilizer-ligands from supported gold nanoparticles. Nat Chem 3(7): 551-556.

7. Sassolas A, Leca-Bouvier BD, Blum LJ (2008) DNA biosensors and microarrays. Chem Rev 108(1): 109-139.

8. Itamar Willner, Bilha Willner, Ran Tel-Vered (2011) Electroanalytical Applications of Metallic Nanoparticles and Supramolecular Nanostructures. Electroanalysis 23(1): 13-28.

9. Fägerstam LG, Frostell-Karlsson A, Karlsson R, Persson B, Rönnberg I (1992) Biospecific interaction analysis using surface plasmon resonance detection applied to kinetic, binding site and concentration analysis. J Chromatogr 597(1-2): 397-410.
10. Leuschner RG, Heidel M, Hammes WP (1998) Histamine and tyramine degradation by food fermenting microorganism. Int J Food Microbiol 39(1-2): 1-10.

11. López-Sabater EI, Rodríguez-Jerez JJ, Roig-Sagues AX, Mora-Ventura MT (1993)Determination of histamine in fish using an enzymic method Food Addit Contam 10(5): 593-602.

12. Gabriele C Chemnitius, Masayasu Suzuki, Kimiyasu Isobe (1992) Thin film polyamine biosensor: substrate specificity and application of fish freshness determination. Analytica Chimica Acta 263(1-2): 93-100.

13.Zhipeng Huang, Nadine Geyer, Peter Werner, Johannes de Boor, Ulrich Gösele (2011) Metal-Assisted Chemical Etching of Silicon: A Review. Advanced materials 23(2): 285-308.

14. Severiano F , Gayou G V L, García G, Delgado Macuil R, Martínez Gutiérrez $\mathrm{H}$, et al. (2017) In situ inclusion of Au nanoparticles in porous silicon structure. Applied Physics A 123(1): 83.

15. Chanseok Hong, Hohyeong Kim, Sunghoon Park, Chongmu Lee (2010) Optical properties of porous silicon coated with ultrathin gold film by RF-magnetron sputtering, Journal of the European Ceramic Society 30(2): 459-463.

\section{Your next submission with JuniperPublishers} will reach you the below assets

- Quality Editorial service

- Swift Peer Review

- Reprints availability

- E-prints Service

- Manuscript Podcast for convenient understanding

- Global attainment for your research

- Manuscript accessibility in different formats

( Pdf, E-pub, Full Text, Audio)

- Unceasing customer service

Track the below URL for one-step submission https://juniperpublishers.com/submit-manuscript.php 